\title{
Ladrão de galinhas: um diálogo sobre a estética no livro de imagem
}

Ladrão de galinhas: a dialogue on aesthetics in the image book

Ladrão de galinhas: un diálogo sobre la estética en el libro de imagen

Carla Carvalho*

Marilia Menon Araújo**

\section{Resumo}

As literaturas cujas narrativas são realizadas exclusivamente pela imagem firmaram, ao longo do tempo, a mesma importância que os demais gêneros disponíveis nos espaços educacionais. Devido a isso, propomo-nos a analisar os atributos estéticos que compõem uma dessas obras, Ladrão de galinha, de autoria de Béatrice Rodriguez (2009), selecionada e enviada pelo Programa Nacional Biblioteca da Escola (PNBE) às redes públicas de Educação Infantil, na edição de 2014. Adotamos como metodologia a abordagem qualitativa, tomando como referencial a semiótica de Barthes (2013b). Utilizamos os conceitos de enunciado, deslocamento e representação, partícipes no processo de significação textual, entendendo que estes contribuem para que os demais atributos estéticos sejam comunicantes eficazes na fruição da literatura visual. Dentre os demais especialistas, apoiamonos no suporte teórico de Collaro (2012), Gomes Filho (2014), Heller (2014), Hunt (2010), Kandinsky (1997), Kant (2013), Linden (2011), Neitzel e Carvalho (2013), Neitzel e Oliani (2008), Nikolajeva e Scott (2011), Santaella (2012), Todorov (2011), Willsberg e Forssman (2007). Constatamos que há uma contínua busca no aprimoramento do livro composto exclusivamente de imagens, que permitem uma apreciação do texto visual para além do entretenimento, tornando-o objeto de fruição pela experiência estética que proporciona. Colocamos em discussão a "leiturabilidade" do texto visual permitindo aceitar, rejeitar, aprimorar e questionar as possibilidades de leitura que mobilizam o pensamento.

Palavras-chave: texto visual, literatura infantil, leiturabilidade, PNBE 2014.

\section{Abstract}

Image-driven literatures have proven, over time, to be of equal importance to other genres available in educational spaces. As such, we propose to analyze the aesthetic attributes that comprise one of these works, Ladrão de galinha (Chicken thief), written by Béatrice Rodriguez (2009), which was selected and sent by the National School Library Program (called PNBE) in 2014 to the public networks of Early Childhood Education. We adopted as methodology a qualitative approach, taking as reference Barthes's (2013b) semiotics. We use the concepts of enunciation, displacement and representation, which contribute to the process of textual signification, understanding that they do so such that other aesthetic attributes are effective communicators in the realization of visual literature. Among the other specialists, we rely on the theoretical support of Collaro (2012), Gomes Filho (2014), Heller (2014), Hunt (2010), Kandinsky

\section{Resumen}

Las literaturas cuyas narrativas son llevadas a cabo exclusivamente por la imagen han tenido, a lo largo del tiempo la misma importancia que los demás géneros disponibles en los espacios educativos. Debido a eso, se propone analizar los atributos estéticos que componen una de esas obras, Ladrón de gallinas, de autoría de Béatrice Rodriguez (2009), seleccionada y enviada por el Programa Nacional Biblioteca de la Escuela (PNBE) a las redes públicas de Educación Infantil, en la edición de 2014. Se adoptó como metodología el abordaje cualitativo, tomando como referencia la semiótica de Barthes (2013b). Se utilizaron los conceptos de enunciado, desplazamiento y representación, partícipes en el proceso de significación textual, entendiendo que éstos contribuyen para que los demás atributos estéticos sean comunicantes eficaces en el goce de la literatura visual. Entre los demás especialistas, recurrimos al soporte teórico de Collaro (2012),

\footnotetext{
* Doutora em educação e professora da Universidade Regional de Blumenau (FURB), Blumenau, SC, Brasil. (Dorcid.org/00000002-1402-7920. E-mail: ca_carvalho@icloud.com

** Mestre em educação e professora da Rede Municipal de Educação de Balneário Camboriú, SC, Brasil. (Dorcid.org/0000-00031693-963X. E-mail: mariliamenon785@gmail.com
} 
(1997), Kant (2013), Linden (2011), Neitzel and Carvalho (2013), Neitzel and Oliani (2008), Nikolajeva and Scott (2011), Santaella (2012), Todorov (2011), Willsberg and Forssman (2007). We have determined that there is a continuous effort to improve this kind of book composed exclusively of images, which allows for appreciation of the visual text beyond entertainment, making it an object of actualization through the aesthetic experience that it provides. We raise the question of "readability" in regards to the visual text so that we might accept or reject, improve or question the possibilities of reading that stimulate thought.

Keywords: visual text, children literature, readability, PNBE 2014.
Gomes Filho (2014), Heller (2014), Hunt (2010), Kandinsky (1997), Kant (2013), Linden (2011), Neitzel e Carvalho (2013), Neitzel y Oliani (2008), Nikolajeva y Scott (2011), Santaella (2012), Todorov (2011), Willsberg y Forssman (2007). Se constató que hay una continua búsqueda por el perfeccionamiento del libro compuesto exclusivamente de imágenes, que permiten una apreciación del texto visual más allá del entretenimiento, haciéndolo objeto de goce por la experiencia estética que proporciona. Se pone en discusión la "lecturabilidad" del texto visual permitiendo aceptar, rechazar, perfeccionar $\mathrm{y}$ cuestionar las posibilidades de lectura que movilizan el pensamiento.

Palabras clave: texto visual, literatura infantil, lecturabilidad, PNBE 2014.

\section{Introdução}

No exercício do magistério junto à Educação Infantil, somos constantemente envolvidos pelas diversas literaturas que integram o acervo das bibliotecas escolares. Se a participação na seleção e na aquisição dos livros não ocorre diretamente, ela acontece depois durante o planejamento das aulas, na elaboração de projetos e no cotidiano da narração de histórias. Cabe a cada professor, em uma regra não escrita, mas presente na vivência de sala de aula, determinar os temas e os gêneros daquelas seletas obras que serão ouvidas e guardadas entre as melhores lembranças da infância.

Em meio a toda tagarelice que há em uma escola, encontros privados da criança com o livro são ainda possíveis, embora venham se tornando, quando não poucos, muito breves. São esses momentos que nos fazem pensar quanto uma história pode trazer inúmeras possibilidades de leitura, tornando conscientes as muitas realidades que se entrelaçam. Tanto autor quanto leitor e ouvinte dirigem, contribuem e interferem na interpretação da história, porque verdade narrativa não é um valor imutável. Então, são esses livros sem letras, ponto ou travessão, livros cuja narrativa foi desenhada, pintada, fotografada, gravada, bordada, cujas cores definem as personagens, cujo cenário se descreve, que se identificam e firmam-se como uma obra aberta. Livros que contam velhas, novas e loucas histórias. São abusados, pois provocam-nos como a Esfinge: ${ }^{1}$ "Decifra-me ou devoro-te". História sem palavra, livro somente com imagens, sobre ele que iremos falar.

\section{Atributos estéticos em história sem palavras}

Ao observar as relações da criança com a leitura e entendê-las como um processo social de comunicação, na qual a experiência estética, segundo Neitzel e Carvalho (2013, p. 1024), "[...] pode ser um meio pelo qual o sujeito percebe melhor a si mesmo e seu entorno", ampliou-nos o interesse nas narrativas somente visuais que os livros pensados para a infância têm contemplado. Com a crescente criação de histórias sem palavras, nas quais a responsabilidade na comunicação pertence à ilustração, uma questão surgiu: Como se organiza a significação estética em um livro de imagem?

Definimos, assim, buscar um livro cujo texto imagético estivesse presente na Educação Infantil, o qual nos levou ao acervo do Programa Nacional Biblioteca da Escola (PNBE). O

\footnotetext{
${ }^{1}$ Personagem mítico grego, o qual desafia o herói em sua missão épica a decifrar seu enigma, sob pena de morte se não cumprida a tarefa.
} 
PNBE seleciona e envia literaturas em diversos gêneros às redes de ensino públicas em todo o país, já há quase duas décadas. Dessa forma, escolhemos para este estudo uma obra no gênero livro de imagem - Ladrão de galinha - de Béatrice Rodriguez, categoria 2 (Pré-escola), edição de 2014. Por ser o texto visual nosso objeto de estudo, buscamos como referência a abordagem semiótica, entendendo ser esta capaz de instrumentalizar a leitura e a interpretação de uma narrativa imagética, extraindo significado em sua forma de expressão, porém sem emoldurá-lo.

Barthes (2013a) é pontual quando fala sobre sua relação intensa com o texto, comparando-o a um objeto fetiche, enfatizando que também é objeto de desejo desse mesmo texto. Concordamos com ele quando diz que o texto, no caso em forma de livro de imagem, é um objeto de desejo, algo que tomamos compulsivamente, a ação dirigida pela emoção. Há, ainda, outro fato sobre o qual o semioticista nos provoca, quando aponta a diferença entre o prazer e a fruição do texto:

Texto de prazer: aquele que contenta, enche, dá euforia; aquele que vem da cultura, não rompe com ela, está ligado a uma prática confortável da leitura. Texto de fruição: aquele que põe em estado de perda, aquele que desconforta (talvez até um certo enfado), faz vacilar as bases históricas, culturais, psicológicas do leitor, a consistência de seus gostos, de seus valores e de suas lembranças, faz entrar em crise sua relação com a linguagem (Barthes, 2013a, p. 20-21, grifo do autor).

Chama-nos a atenção a palavra "confortável", porque, se há um domínio na escrita, este é o seu maior e mais contundente poder: selecionar as palavras que ficam e as que saem do texto. Não há lugar para ingenuidade no universo das letras, apenas sagacidade. O conforto predispõe-nos ao relaxamento, à confiança, à continuidade do que já é conhecido. Não buscamos, nem esperamos algo novo; estamos satisfeitos. Uma prática confortável de leitura acontece quando não se espera que se diga mais nada do que já se sabe. Então, para que continuar lendo?

Tomando como pressuposto o conceito da psicologia da percepção de que vemos sempre somente o que sabemos, começamos a desfiar a trama que envolve a feitura de uma narrativa cujas protagonistas são as imagens. Neitzel e Oliani (2008) afirmam que o texto literário vai além de ser um instrumento utilitário de comunicação, por isso a urgência em promovê-lo como objeto estético. As autoras justificam lembrando que se convencionou abordar a literatura de forma didática e estruturalizada, dificultando a apreciação individual do livro como obra de fruição. Assim, interrogamo-nos sobre quais seriam as características predominantes contidas nesse gênero literário, fazendo-nos buscar os elementos que o compõem esteticamente - o que há em comum, independentemente do estilo de cada autor/ilustrador. Buscamos a palavra de especialistas relacionada à composição de atributos estéticos que qualificam uma obra de literatura infantil, que, em conjunto, constroem significação ao texto ilustrado.

A estética da significação, segundo Barthes (2011), coloca a questão sobre cada detalhe ser imprescindível na narrativa, ou seja, cada pormenor do texto contém um significado. O autor considera que a significação de um texto está presente nele todo, do início ao fim, sem partes especiais, porque o encadeamento narrativo se faz a cada palavra ou imagem e a cada nível de entendimento. "A arte [...] é um sistema puro, não há jamais unidade perdida, por mais longo, por mais descuidado, por mais tênue que seja o fio que a liga a um dos níveis da história" (Barthes, 2011, p. 29). O autor ainda defende que são três as forças na literatura: a enunciação, a representação e o deslocamento (Barthes, 2013b). A enunciação é a própria verdade do sujeito, reconhecendo a linguagem tal como se apresenta, com familiaridade. Procura o sabor e saber das palavras. A segunda força consiste na representação do real: este é seu objeto de desejo; e isso só é possível por meio da literatura, quando busca aproximar-se da realidade de quem escreve, de quem o lê. A terceira força da literatura, o deslocamento, é o próprio jogo semiótico, no qual os signos serão movidos, deslocados, para outro significado que não o esperado a princípio.

Todorov (2011), em consonância, diz que a narrativa é uma convenção na apresentação das personagens e fatos em si. Existe como abstração, não na realidade dos acontecimentos. Caracterizam essa dinâmica as repetições, seja por gradação, seja por paralelismo, pois: “Em toda obra, existe uma tendência à repetição, que concerne à ação, as personagens ou mesmo a detalhes da descrição" (Todorov, 2011, p. 223). Para evitar ou quebrar a monotonia no desenrolar do enredo, o recurso de repetição por gradação é utilizado, e, a cada período, seja de uma oração ou 
de um capítulo, um novo elemento é acrescentado à ação, encadeado ao que vem a seguir. Outra repetição, a mais frequente na literatura, ocorre por paralelismo, como o nome já diz, acontece ao mesmo tempo pelo menos duas ações concomitantes, com semelhanças e diferenças.

Santaella (2012) apresenta-nos algumas especificidades na leitura de uma imagem, que se opõem ao texto verbal, tais como: a percepção simultânea do todo da imagem, sem prender-se aos detalhes no primeiro momento - princípio da representação daquilo que designa; possui melhor representação espacial-visual; representa essencialmente o que é visual; não representa negação ou relação causal; realiza elaboração cognitiva pelo hemisfério cerebral direito responsável pelas emoções; maior rapidez na atenção e na memorização.

A cor, outro atributo básico na composição estética de um livro ilustrado, tem exercido influência no comportamento e no sentimento desde o nascimento de cada pessoa, independentemente de gênero, de idade ou de nacionalidade. A sua força cultural é tamanha que nos acostumamos a vê-la como inata, e não como outro conteúdo apreendido socialmente. Na pesquisa de Heller (2014), realizada na Alemanha, dois mil homens e mulheres com idades entre 14 e 97 anos, atuantes em 219 profissões distintas, foram inquiridos sobre o impacto psicológico das cores, sobre as causas atribuídas as suas preferências, e os sentimentos relacionados a cada cor mencionada.

Os resultados das pesquisas demonstram que cores e sentimentos não se combinam ao acaso nem são uma questão de gosto individual - são vivências comuns que, desde a infância, foram ficando profundamente enraizadas em nossa linguagem e em nosso pensamento (Heller, 2014, p. 17).

Constatou-se que as cores azul, verde, vermelho, preto e amarelo, nessa ordem, estão entre a preferência dos entrevistados. Também se posicionam abaixo de $8 \%$ das menos apreciadas, isto é, não estão entre as cinco cores mais rejeitadas. A pesquisadora traz, ainda, algumas considerações acerca da relação das crianças com essa cor, pois são: comumente a primeira cor ensinada; relacionam a cor a alimentos doces; pensar em vermelho e citá-lo equivale a pensar em cor; não demonstram preferência por essa cor quando pintam. "Os efeitos das cores não são congênitos, do mesmo modo como a linguagem também não o é. Mas como nós a aprendemos desde pequenos, os significados se tornam tão interiorizados nos adultos, que dão a impressão de serem inatos" (Heller, 2014, p. 54).

Em continuidade, para Linden (2011), o livro composto significativamente de imagens traz características próprias na construção do texto. Um dos desafios está na capacidade criativa de cada autor em representar o tempo e o espaço, pois este se apresenta em uma narrativa estática, mas sem torná-lo uma imitação do discurso alfabético, nem perder sua riqueza expressiva. Ela nos oferece alguns recursos de identificação na leitura de imagens:

- Instante capital: concentra e representa todas as características essenciais de um acontecimento em uma cena.

- Instante qualquer: representa a ideia de um acontecimento natural, algo que está se desenvolvendo sem pressa, em ritmo próprio; há mais descrição do que ação.

- Instante movimento: condensa as ideias contidas nos momentos anteriores, mas com ênfase no fluxo gestual.

As mais eficazes são as imagens que trazem uma ação que precede de imediato seu ponto culminante. No gesto de lançar, o ilustrador não irá escolher o momento do impulso, e sim aquele em que o antebraço está dobrado, preparando-se para o movimento (Linden, 2011, p. 104).

A imagem sangrada, aquela sem limites de moldura ocupando todo o espaço, muito presente nas histórias com páginas duplas, empresta um ritmo singular à leitura. Caracterizam-se ainda, embora não seja regra, as páginas pares e impares de um livro ilustrado como indicadores narrativos - "[...] a par cria uma sensação de segurança, enquanto a ímpar traz perigo e agitação" (Nikolajeva e Scott, 2011). Também integra a narrativa do texto a criação de um ambiente (cenário), quer seja ele simples ou complexo, emprestando força às ações das personagens. E, ao contrário das palavras que podem somente descrever um local ou paisagem, a imagem efetivamente irá mostrá-lo. Para Nikolajeva e Scott (2011, p. 85, grifo das autoras): “A representação visual do cenário é inenarrada e, por isso, não 
manipuladora, dando ao leitor considerável liberdade de interpretação". Agora, façamos uma leitura a partir de atributos estéticos de um livro de imagem cujas personagens já fazem parte da infância de incontáveis crianças em nosso país.

\section{Ladrão de galinha, uma história sem palavras}

A obra de Béatrice Rodriguez (2009) toma o paradigma da natural rivalidade ou distanciamento entre espécies diferentes e a transforma em um relacionamento romântico, provocando um deslocamento no comportamento das personagens envolvidas (Barthes, 2013b). Uma narrativa de temática pouco usual na literatura infantil, possibilitando a cada leitor intuir um significado ao drama narrado. Ainda assim, essa liberdade não será absoluta, pois as normas sociais controlam as interpretações, mesmo que não sejam percebidas como tal (Hunt, 2010). O estilo da autora mostra um desenho despojado, preferindo a minimidade nos contornos (Gomes Filho, 2014) e uma ausência de ousadia na escolha cromática, com exceção de uma página dupla, a qual veremos adiante. Nas demais, predominam cores sóbrias, esmaecidas. A atenção do leitor prende-se aos cenários inusitados e às ações dinâmicas que as personagens desenvolvem.

Em formato estreito e comprido, sendo preciso segurá-lo com ambas as mãos, o livro, embora leve, chama a atenção pela inesperada capa dura de alta gramatura (Collaro, 2012), portanto resistente ao uso diário (Figura 1), e pelo miolo em papel fosco. A primeira impressão ao pegá-lo fechado é de que faltam páginas, pois se sente apenas as capas, mas depois lembramos que uma forma compacta tem como propósito proteger seu conteúdo.

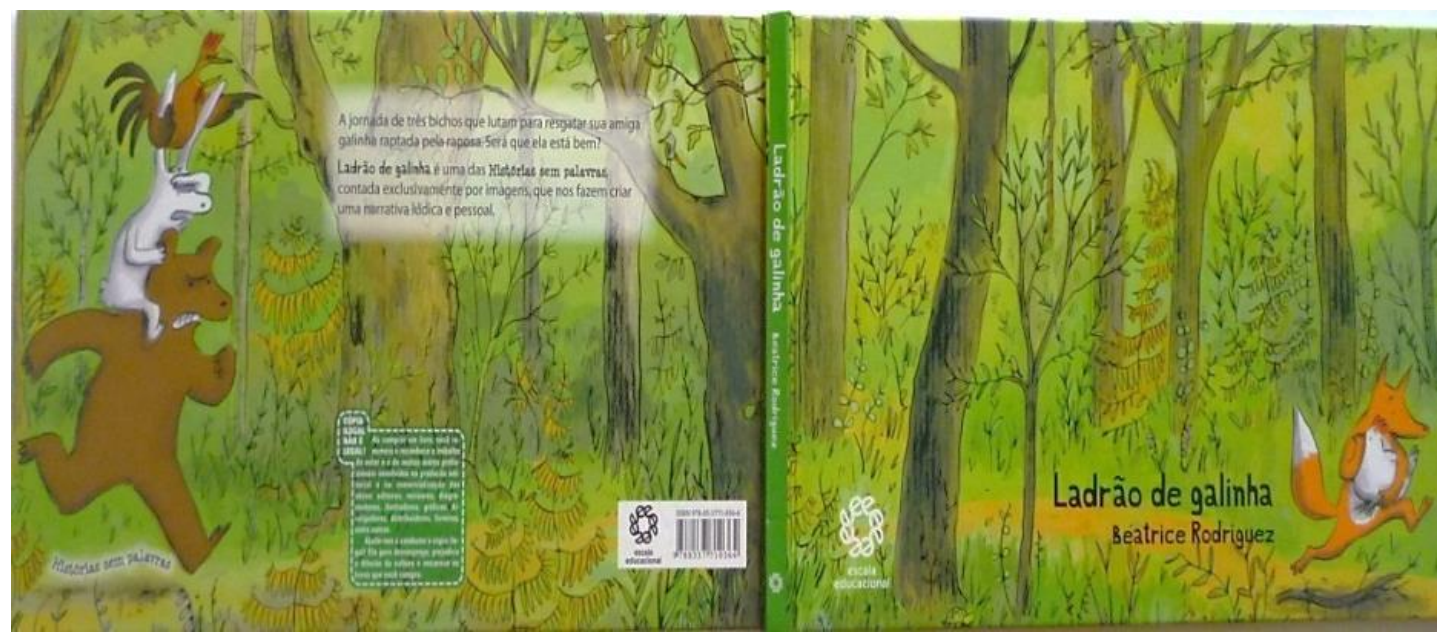

Figura 1 - Capa e contracapa de Ladrão de galinha. Fonte: Rodriguez (2009).

O livro está em conformidade com o disposto pelo edital de seleção (Brasil, 2012) quanto ao projeto gráfico, pois este requer durabilidade e segurança, o que pode ser visto também nas páginas costuradas e não grampeadas desse livro. Além disso, a forma longilínea corrobora com a proposta de determinação e movimento contínuo que a narrativa assume. Contudo, essa encadernação é vista nas edições adquiridas diretamente no mercado. As publicações enviadas às escolas apresentam diferenças quanto ao tamanho, um pouco mais largas, e as capas confeccionadas em brochura. O miolo ganhou páginas em papel couchê brilhante, mais eficiente na impressão de imagens (Willberg e Forssman, 2007), e parte do título no plural (Ladrão de galinhas), sob a publicação da editora Raposa Vermelha. A visibilidade das cenas, com maiores detalhes, tornou-as mais atrativas. Exceto esses itens, nada referente ao tema e às ilustrações foi alterado na versão enviada pelo PNBE. No mais, as obras enviadas às escolas apresentam melhor qualidade estética, 
As páginas são em sua maioria duplas, com as imagens sangradas. A exceção ocorre na primeira página (Figura 2), independente das outras, cujo desenho foi emoldurado, reforçado por um fundo branco e retângulo verde; uma cena bucólica, um déjà vu de fábulas e contos de fadas. Contudo, se o leitor aproximar o olhar, verá detalhes na cena que não pertencem aos clássicos. Foram acrescidos objetos contemporâneos: caminhão guincho, bicicleta, mesa e cadeiras com linhas leves tubulares, plurissignificando a leitura. A liberdade estética da autora ainda permitiu colocar uma inusitada janela em um telhado aparentando palha, com vista para o alto. Uma irônica impossibilidade arquitetônica.

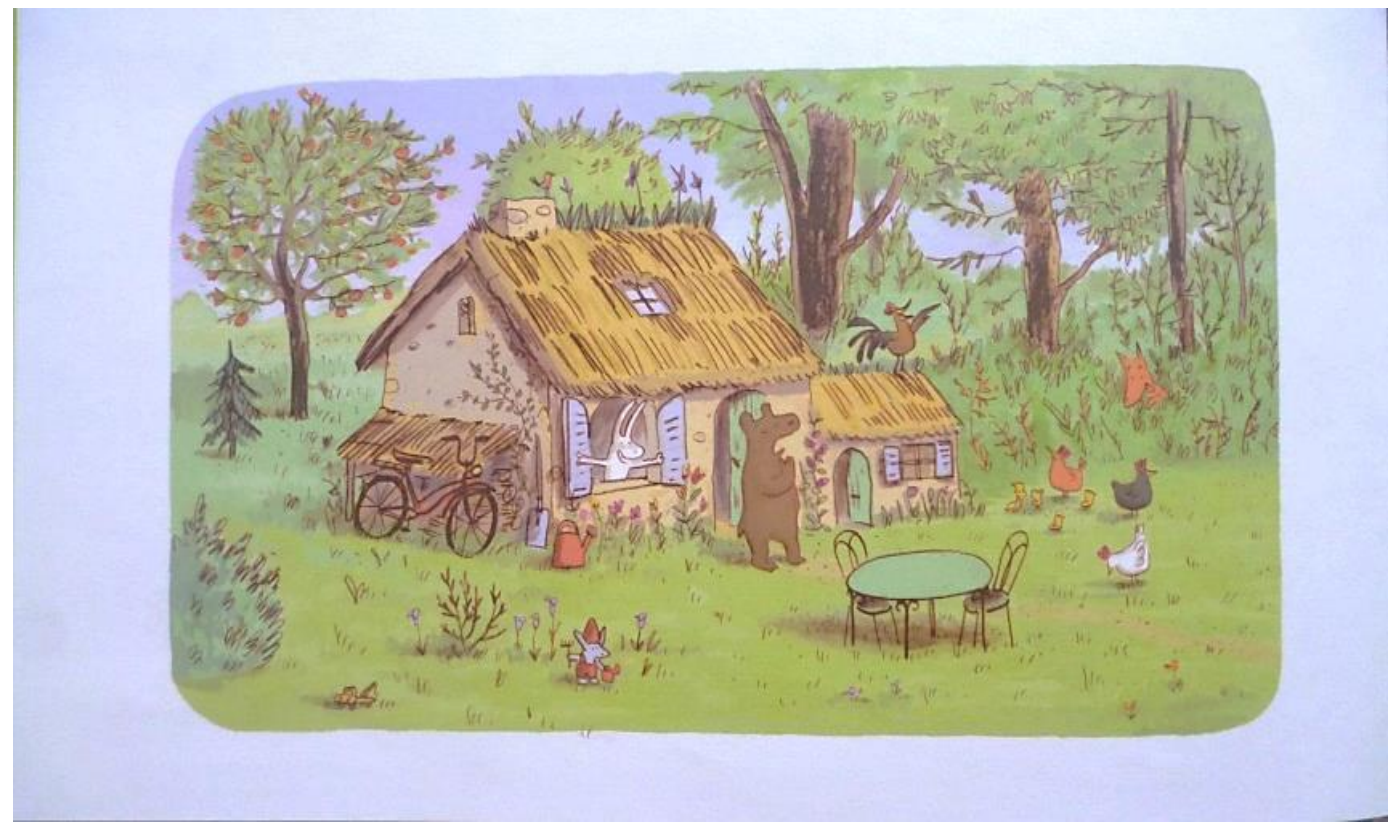

Figura 2 - Página emoldurada em Ladrão de galinha. Fonte: Rodriguez (2009).

Todas as personagens são antropomórficas, assumem características humanas nos sentimentos e nos comportamentos. Elas não agem individualmente, pois são vistas sempre com seus pares. De um lado o trio formado pelo urso, coelho e galo; e, no outro, a dupla entre a raposa e a galinha. A presença de ambos é constante, em todos os cenários; trio à esquerda e dupla à direita das páginas duplas. Eles caracterizam o que Todorov (2011) denomina como repetição por paralelismo, em que dois grupos de atores atuam no mesmo tempo narrativo, o que acentua suas semelhanças e diferenças. Isso leva principalmente àquilo que trará amplitude à leitura: os sentimentos conflitantes que movimentam a ação.

A raposa e a galinha (Figura 3), personagens comuns nas fábulas pela sua notória rivalidade, são vistas juntas em todas as cenas, inicialmente a contragosto, depois no colo, mais adiante lado a lado e, por fim, abraçadas. Parte delas a grande mudança no percurso narrativo, a qual Barthes (2013b) se refere como um deslocamento de sentido. A posição que a raposa possui de início como vilã, perde força expressiva depois do ato inicial do rapto da galinha; e esta é quem acaba assumindo um lugar ativo na finalização da história, abandonando o papel de vítima (Figura 4) e defendendo sua própria posição. A simplicidade do desenho sem volume ou espessura não impede de revelar a mudança sutil, mas gradativa das personagens. As cores laranja e branco favorecem a sensorialidade, trazendo luminosidade aos cenários, considerando que estes foram traçados em tons escuros e monótonos. 

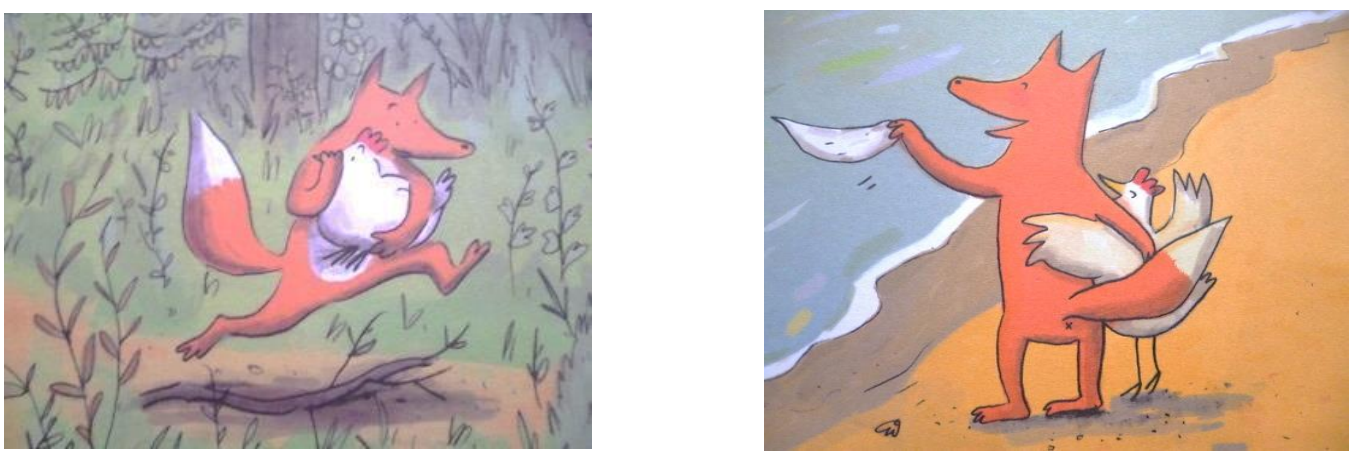

Figura 3 - Detalhes - Deslocamento em Ladrão de galinha. Fonte: Rodriguez (2009).

Outra exceção na diagramação das páginas (Figura 4) acontece quando o emolduramento ocorre de maneira bastante distinta da Figura 2 anterior. São quatro cenas figurando as mesmas personagens e um plano de fundo amarelo. A sequência narrativa torna-se detalhada, e a intencionalidade estética realiza-se por meio das expressões corporais as quais são acentuadas pela cor de fundo, que se torna elemento unificador dos quadros. Segundo pesquisa de Heller (2014), o amarelo é considerado a cor mais contraditória, podendo significar jovialidade, ludicidade, impulsividade; e, também, irritação, desprezo e traição, sentimentos presentes na relação entre as personagens.

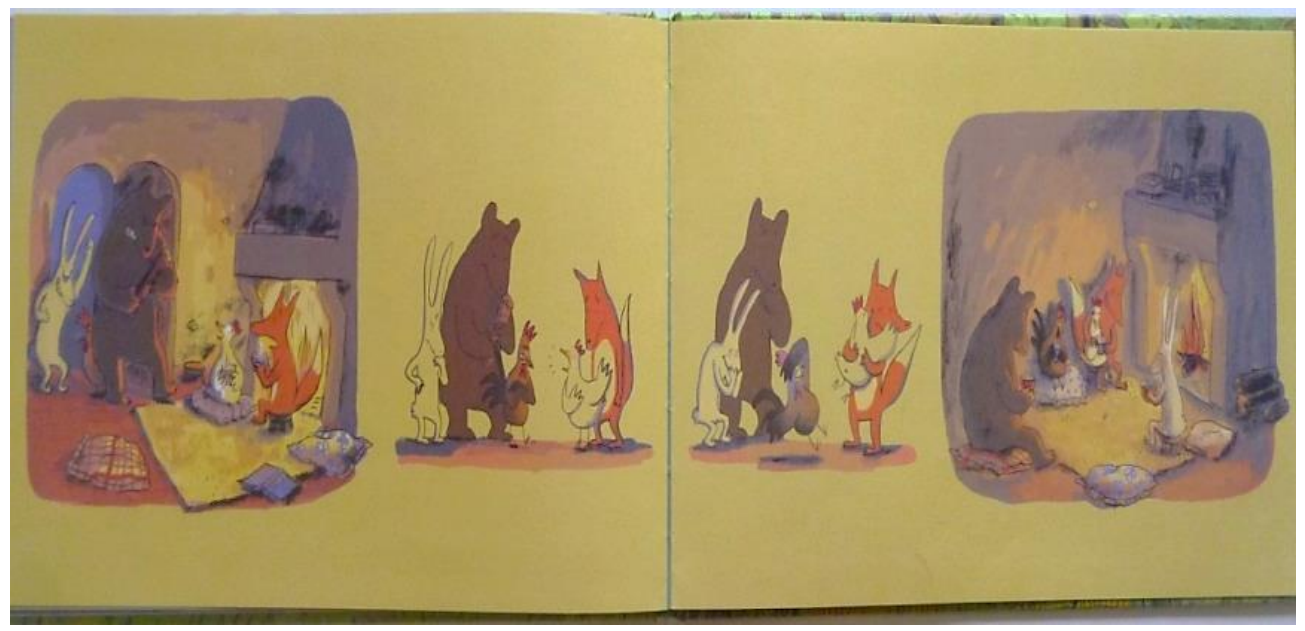

Figura 4 - Instante capital em Ladrão de galinha. Fonte: Rodriguez (2009).

O clímax, no qual todos enfim se reencontram, também caracteriza-se como um instante capital (Linden, 2011), o momento decisivo. No entanto, o confronto esperado é diluído pelas cenas seguintes, $2^{\circ}$ e $3^{\circ}$ quadros (Figura 4 ), em que a argumentação emotiva realizada pela galinha desfaz a intenção belicosa dos recém-chegados, culminando em uma inusitada reunião familiar. A maneira como essa cena foi pensada trouxe para a mesma página dupla clímax e epílogo; confronto e conciliação. Uma conclusão um pouco rápida - e fácil - demais.

Quanto ao trio de amigos: urso, coelho e galo (Figura 5), estes exibem a maior variedade de expressões, mas sempre em conjunto, como se fossem uma só unidade (Gomes Filho, 2014). As cores marrom e branca não causam impacto, tampouco a forma estilizada de seus corpos. Exceto pelo traçado alongado nos focinhos dos animais, até mesmo no bico das aves, que é uma característica autoral. Para Kandinsky (1997), a posição à esquerda, onde essas personagens aparecem em todas as páginas, possui um potencial sentido de liberdade, de experienciar 
outros modos de ver e sentir. No entanto, em conflito com a estabilidade, pois correm para a direita, em uma tentativa de permanência do que era antes. A sensibilidade expressa esteticamente evidencia-se na harmoniosa relação entre os três.

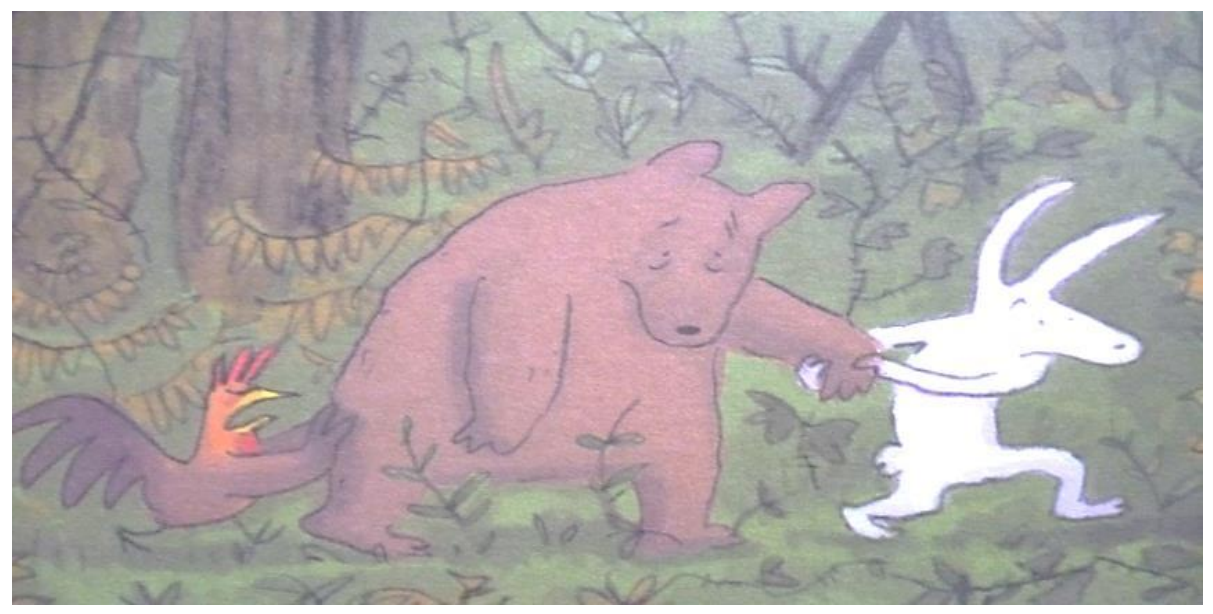

Figura 5 - Detalhe - Trio de amigos em Ladrão de galinha. Fonte: Rodriguez (2009).

Segundo Linden (2011), um instante movimento caracteriza-se como este da Figura 6, a qual em página dupla apresenta dois cenários: céu e mar. Eles mudam, estando os céus à esquerda, com nuvens carregadas, e as mesmas cores da água; e a direita mostrando-se aberto e claro. Quanto ao mar, águas revoltas de um lado, linhas criando ondulações, aliadas aos tons frios e opacos, unem-se na ideia de perigo e de enjoo; e, do outro lado, águas mais brandas, propícias à navegação. Duas silhuetas de peixe foram insinuadas, em formas e tamanhos diferentes, o que não contribuiu à temática nem a estética. Relevante são as personagens, totalmente opostas nas atitudes e nas expressões. O detalhe dos óculos escuros da galinha, como uma turista em uma gôndola veneziana, corrobora com o aspecto cômico-trágico dessa imagem, cujos personagens esforçam-se ao máximo para resgatar alguém que nitidamente não deseja mais voltar.

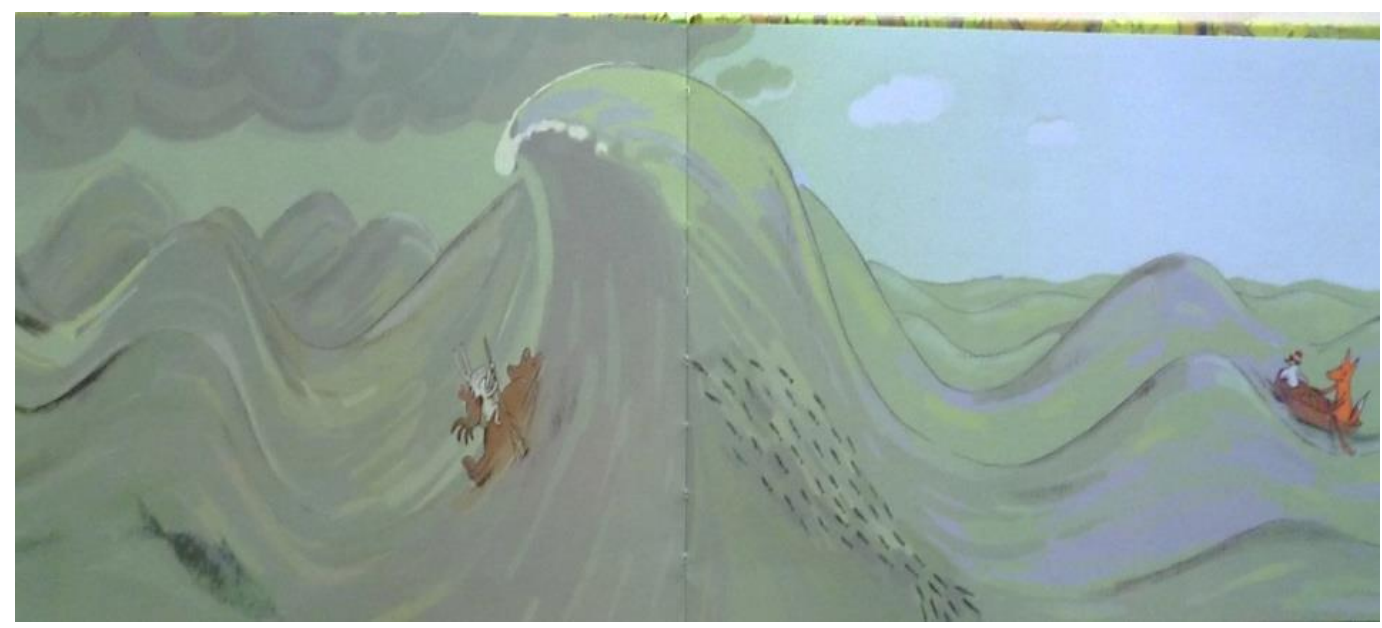

Figura 6 - Instante movimento em Ladrão de galinha. Fonte: Rodriguez (2009).

Quanto ao instante qualquer (Linden, 2011), selecionamos a imagem de um inocente jogo de xadrez (Figura 7). Contudo, torna-se absurdo quando a partida acontece durante uma fuga, dentro de uma montanha. A autora continua a brincar com seus leitores, pois especialmente 
este jogo possui uma tradição preferencial entre adultos escolarizados. Se cada quadro narrativo traz uma aproximação dessas personagens, parece-nos que aqui a narrativa argumenta sobre a possibilidade de um entendimento intelectual entre díspares. Ou simplesmente um nonsense (Nikolajeva e Scott, 2011) em cuja imagem deliberadamente o significado foi omitido.

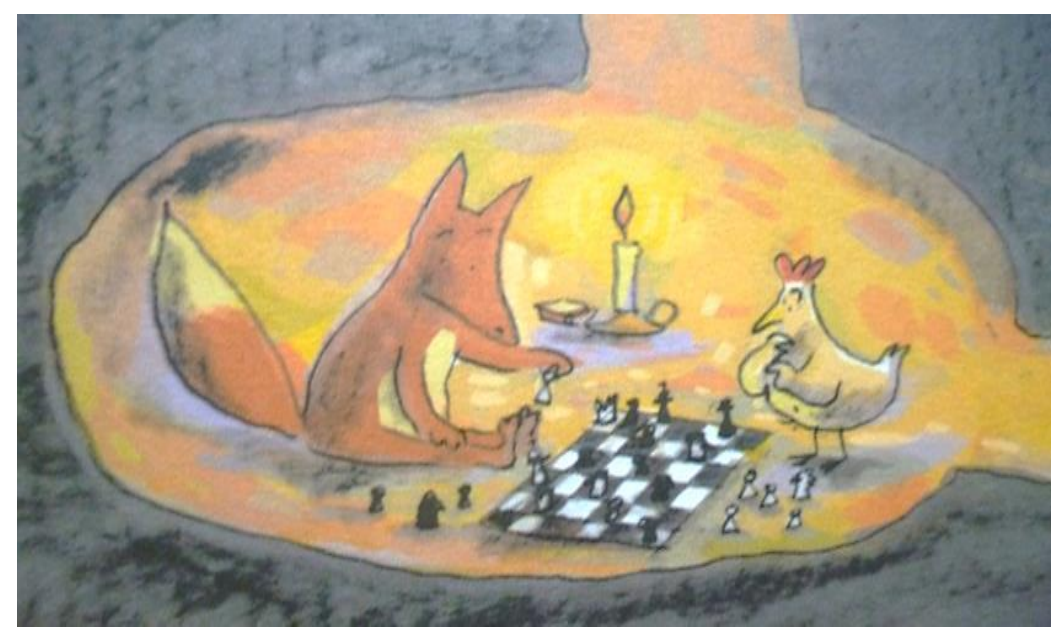

Figura 7 - Detalhe - Instante qualquer em Ladrão de galinha. Fonte: Rodriguez (2009).

A variedade de cenários recebeu amplo espaço em todo o livro, mesclando imagens figurativas e simbólicas (Santaella, 2012). O primeiro a ser explorado, desde a capa, é a floresta cujas linhas verticais dos troncos das árvores vazam das páginas sugerindo continuidade e atenuando a ideia de fechamento (Gomes Filho, 2014) na forma e na leitura. O tempo passa do dia para noite, e a primeira impressão é a de que toda a narrativa ocorrerá dentro da mata.

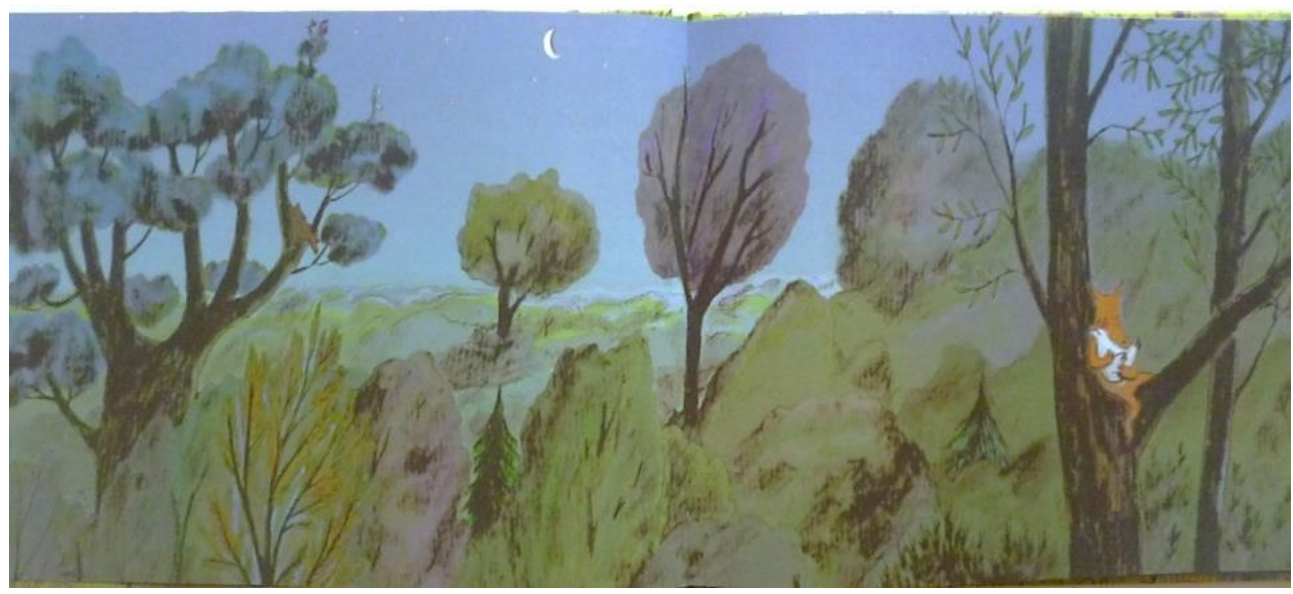

Figura 8 - A floresta em panorâmica em Ladrão de galinha. Fonte: Rodriguez (2009).

Até que, no momento seguinte (Figura 8), a ação inverte-se: as personagens são colocadas em cima, sobre a copa das árvores. A claustrofobia da mata cerrada é aliviada pelo espaço que se abre; contudo, a sensação de isolamento se intensifica. Longe do lar, buscando o que foi perdido, contemplar a vastidão parece não confortar. A apresentação estética dessa página também muda, não em relação às cores, que continuam sóbrias, mas na técnica utilizada, agora aparentando monotipia, devido às marcas que foram deixadas no papel. A técnica 
artística e os materiais utilizados deveriam ser mencionados na obra, conforme prediz o edital de seleção dos acervos, o que não ocorreu.

Outro cenário, uma cadeia de montanhas que propositalmente podem ser visualizadas dentro, acima e a distância (Figura 9), está nas cores azul e cinza majoritariamente, o que mantêm o ritmo de fria expectativa, solicitando também ao leitor que observe, repouse e espere. Os dois círculos de cores quentes, se pequenos em relação à paisagem, menores ainda os que neles estão; um pouco do melhor do humano, onde há trégua e esperança. Uma imagem que pode ser considerada acrônica, segundo Nikolajeva e Scott (2011), pois é uma página atemporal, podendo ser deslocada para outro lugar da história.

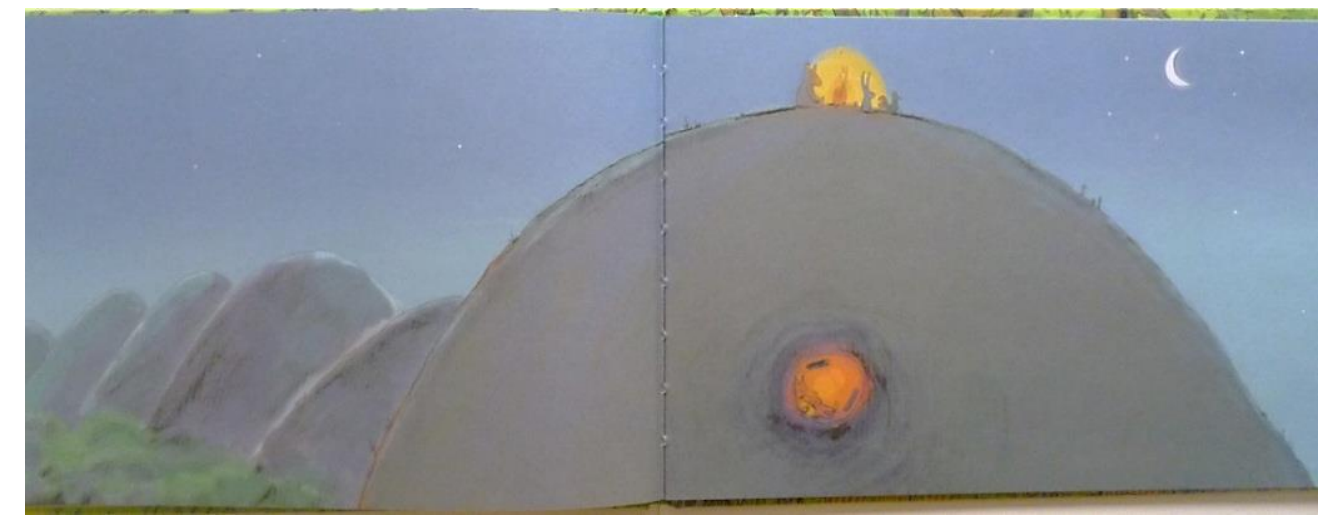

Figura 9 - As montanhas em Ladrão de galinha. Fonte: Rodriguez (2009).

A paisagem seguinte, a praia, vem com as cores quentes do amanhecer (Figura 10). Enquanto ela se abre em calmas linhas horizontais, o contraste ocorre no súbito movimento das personagens.

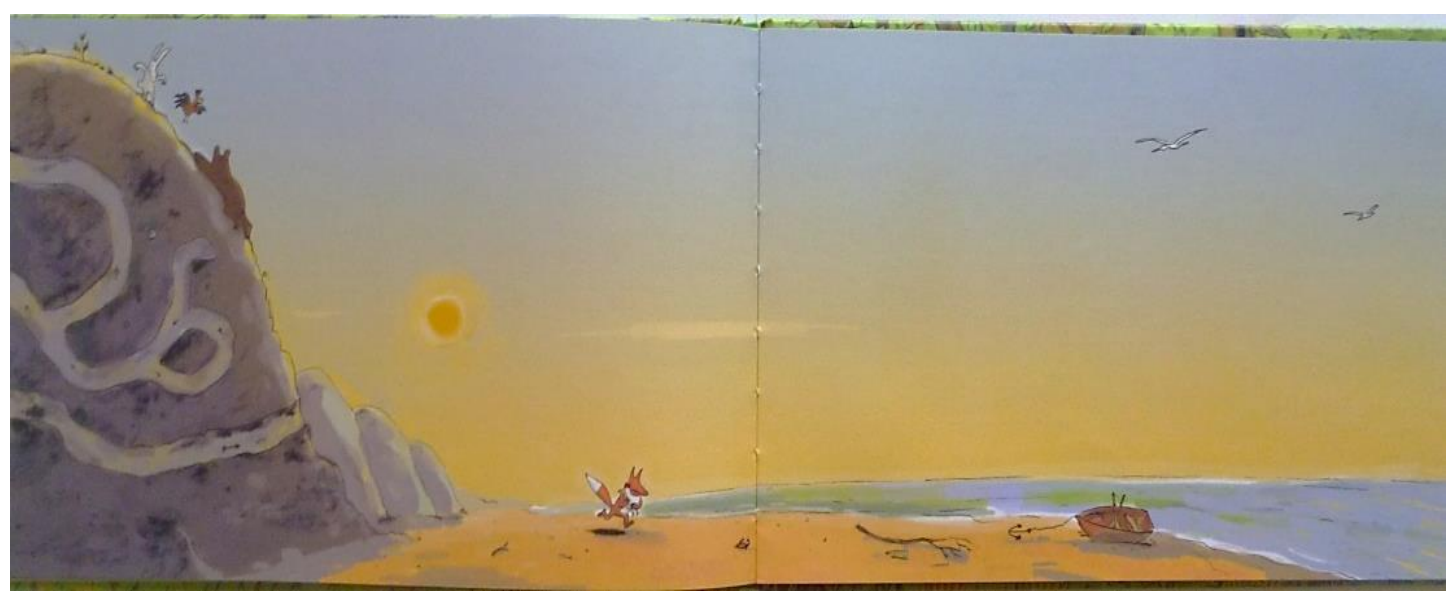

Figura 10 - A praia em Ladrão de galinha Fonte: Rodriguez (2009).

Na Figura 11, a única página dupla na qual o trio aparece em ambos os lados, direita e esquerda, e sem a presença das outras personagens. Nesse caso, houve uma ênfase na importância e na perseverança destas para a história, pois aqui protagonizam o anticlímax. A casa situada abaixo das raízes de uma árvore faz outra referência à fantasia dentro da fantasia, embora não seja uma ideia inédita. No interior, como vimos na Figura 4, uma aconchegante lareira acesa. Para lembrarmos de que o insólito da arte é o que também a faz ser denominada assim. 


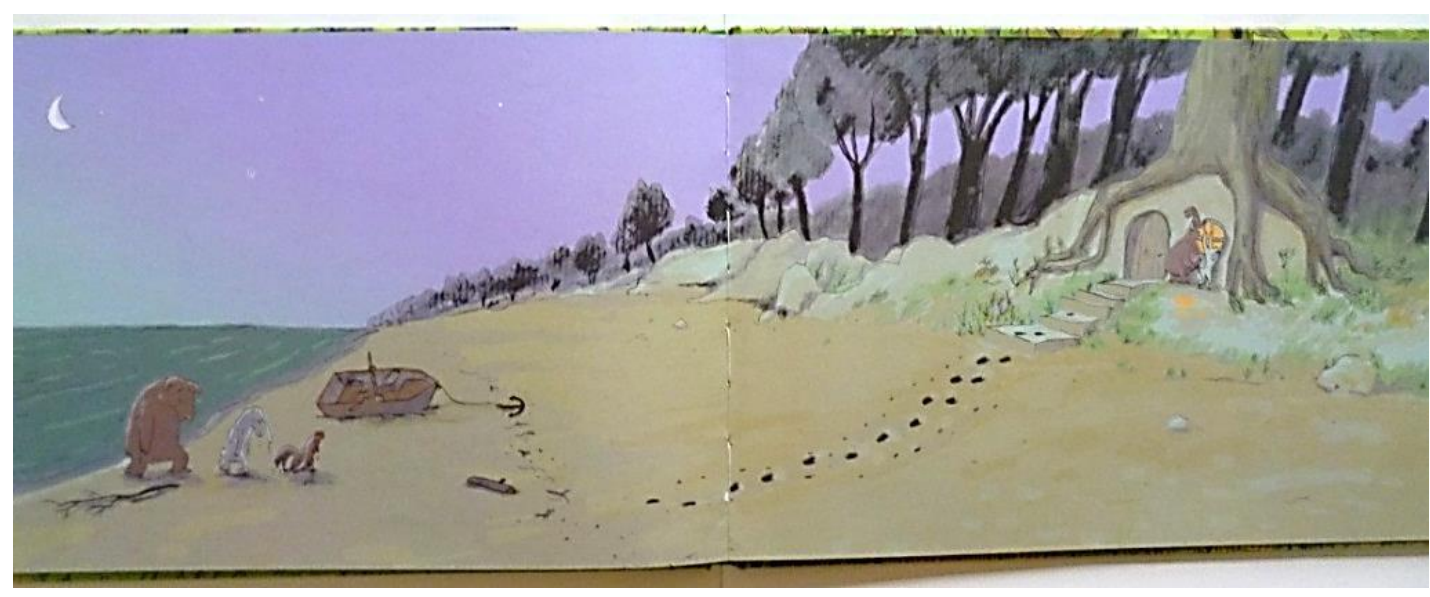

Figura 11 - A casa na árvore em Ladrão de galinha. Fonte: Rodriguez (2009).

Para Hunt (2010), no percurso de um livro, estão envolvidos três elementos: a criança, o autor e a editora; e que mesmo neste século, a literatura infantil ainda figura entre as mais conservadoras entre seus pares. Essa história parece romper em parte com esse enunciado. Ela mantém o final feliz esperado, talvez porque, além de agradar ao mercado editorial, essa seja uma prerrogativa humana, a de buscar um bem maior em todas suas relações. Por outro lado, não busca uma estética da beleza (Kant, 2013), mas, por certo, um gosto, um agradar subjetivo, mas aceito, presente em suas formas e cores estilizadas, conseguindo, assim, comunicar eficazmente sua intenção. As personagens icônicas, que já protagonizaram muitas histórias verossímeis ou fantásticas, em outros tempos e autores, não perderam sua força de encantamento, somente foram contextualizadas. Poderíamos situar o livro naquilo que Barthes (2013a) denomina de texto de fruição, para além do texto de prazer, ou seja, aquele que se dispõe a provocar o desconforto do leitor e inquiri-lo em suas recordações e predisposições culturais.

\section{Considerações finais}

Buscamos, neste artigo, pela capacidade expressiva e independente que a leitura estética de uma narrativa visual possui, algo que nos permitisse aumentar a possibilidade de aceitar, rejeitar, aprimorar e questionar a "leiturabilidade" de qualquer texto visual; algo que nos tirasse do centro, e cuja maior permanência independesse da lista das obras mais requisitadas. Ladrão de galinha, expressivamente contemporâneo, brinca com seus traços minimalistas, sua tabela de cor despretensiosa, indiferente à coerência temporal e espacial. Tudo isso já se viu antes, o que desestabiliza é a união de antagônicos, e a quase verossimilhança com a realidade. Uma experiência semiótica de aproximação com o real por meio da ludicidade.

\section{Referências}

BARTHES, Roland (2013a). O prazer do texto. São Paulo: Perspectiva.

BARTHES, Roland (2013b). Aula. São Paulo: Cultrix.

BARTHES, Roland et al (2011). Análise estrutural da narrativa. Tradução de Maria Zélia Barbosa Pinto. Petrópolis: Vozes.

BRASIL (2012). Ministério da Educação. Edital de convocação 04/2012 - CGPLI. Disponível em: http://goo.gl/uaXm8h. Acesso em: 22 ago. 2015. 
BRASIL (2014). Programa Nacional Biblioteca da Escola. Guia 1 - PNBE na escola: literatura fora da caixa. Brasília: Ministério da Educação, Secretaria de Educação Básica.

COLlARO, Antonio Celso (2012). Produção gráfica: arte e técnica na direção de arte. São Paulo: Pearson.

GOMES FILHO, João (2014). Gestalt do objeto: sistema de leitura visual da forma. São Paulo: Escrituras.

HELLER, Eva (2014). A psicologia das cores: como as cores afetam a emoção e a razão. Tradução Maria Lúcia Lopes da Silva. São Paulo: Gustavo Gili.

HUNT, Peter (2010). Crítica, teoria e literatura infantil. São Paulo: Cosac Naify.

KANDINSKY, Wassily (1997). Ponto e linha sobre plano. São Paulo: Martins Fontes.

KANT, Immanuel (2013). Crítica da razão pura. Tradução e notas de Fernando Costa Mattos. 3. ed. Petrópolis: Vozes; Bragança Paulista: Editora Universitária São Francisco. (Coleção Pensamento Humano).

LINDEN, Sophie Van der (2011). Para ler o livro ilustrado. Tradução de Dorothée de Bruchard. São Paulo: Cosac Naify, 2011.

NEITZEL, Adair de Aguiar; CARVALHO, Carla (2013). A estética na formação de professores. Revista Diálogo Educacional, Curitiba, v. 13, n. 40, p. 1021-1040, set./out.

NEITZEL, Adair de Aguiar; OLIANI, Rita de Cássia (2008). Literatura como fenômeno estético. In: ANPED SUL - SEMINÁRIO DE PESQUISA EM EDUCAÇÃO DA REGIÃO SUL. Pesquisa em Educação e Inserção social. 7. Anais eletrônicos. Itajaí: UNIVALI. Disponível em: https://bit.ly/2zZ1vaw. Acesso em: 10 mar. 2017.

NIKOLAJEVA, Maria; SCOTT, Carole (2011). Livro ilustrado: palavras e imagens. Tradução de Cid Knipel. São Paulo: Cosac Naify.

RODRIGUEZ, Béatrice (2009). Ladrão de galinha. São Paulo: Escala Educacional.

SANTAELLA, Lúcia (2012). Leitura de imagens. São Paulo: Melhoramentos.

TODOROV, Tzvetan (2011). Análise estrutural da narrativa. Petrópolis: Vozes.

WILLBERG, Hans Peter; FORSSMAN, Friedrich (2007). Primeiros socorros em tipografia. São Paulo: Rosari. 